Stand Up to Cancer 2012 \& 2014: the medical telethon as UK public service broadcasting in a neo-liberal age.

\title{
Diane Charlesworth
}

University of Lincoln, UK

\begin{abstract}
In a fragmenting attention economy, the stakes for television and for the public service broadcaster are particularly high. This article looks at the different strategies at play in the British broadcaster C4's adaptation of the US-originated Stand Up to Cancer telethon format to present its particular voice and brand in this ecology. This intervention into the politics of medicine is analysed in relation to the discourses of neo-liberalism which, it is argued, have increasingly become part of the mode of address of British factual television content and have increasingly defined the working of the country's national health system.
\end{abstract}

\section{Keywords}

Telethon; UK public service broadcasting; television personality; comedy; cancer.

The UK public service broadcaster Channel Four (hereafter: C4) has in recent years been instrumental in making medical issues and debates about health a key strand of its factual television provision commissioned from the UK independent production sector. Some programmes have approached the issue tangentially. So, for example, some of the campaign documentaries by the television chef, Jamie Oliver (Jamie's School Dinners (2005) and Jamie's Ministry of Food (2008)), have looked, in the former, at the impact of government policy on the provision of school dinners on children's food awareness, health and 
concentration and, in the latter, linked the cooking ability of parents to the general health and well being of families and the larger community. A more recent example is Oliver's campaign, made visible through the one-off documentary Jamie's Sugar Rush (2015), to reduce levels of child obesity and type two diabetes, with a tax on sugary drinks and the introduction of a traffic light system on packaging as part of consumer education. The broadcaster takes a more traditional observational documentary approach in its commissioning of the series, One Born Every Minute (2010-present), a programme that creates a 'spectacle of the female body in pain' in representing pregnant women's 'negotiat[ion] [of] the complex matrix of midwife, doctor and the hospital setting of the National Health Service' (O’Brien Hill, 2014: 199; see also Horeck in this issue). The modality of this series is different to, yet inflected by, two key series in C4's portfolio, Embarrassing Bodies (2007-15) and Supersize vs. Superskinny (2008-present) (for further analysis, see Leadley, 2015) These medical examples of Reality TV (RTV) are instructional, authoritative, 'clinical' in discursive tone whilst voyeuristic, resembling the 'freakshow' in their visuality (see Dovey, 2000; Corner, 2002). These latter two programmes in particular are indicative of the pressure on television as a medium, as it moved into the digital age, to demonstrate its continuing power to speak to and for audiences. For a public service broadcaster (which all domestic broadcasters in the UK are to a greater or lesser degree), in the factual genre it became an issue of balancing 'discourses of sobriety' with 'diversion', those moments described by John Corner as 'high intensity,' 'anecdotal knowledge' and 'snoopy sociability' (2002: 260). C4, as a relative latecomer to the British broadcasting ecology and having to work hard for funding since the start of the new millennium, demonstrated itself very much aware of the need to reassess its particular form of public service and public value and to adapt the brand in order to survive. Survival, for the channel's Chief Executives Mark Thompson (2002-4) and Andy Duncan (2004-9), was to contest the 
BBC's sole call on the licence fee paid by the British taxpayer. This contestability strategy was dropped at the same time as a commitment to public service was re-stated by David Abraham, the latest incumbent of the post (2010-present). As he phrased it, C4 would be 'putting away the begging bowl' (Abraham, 2011). In her account of the Channel's development from its establishment in 1982 the Guardian journalist Maggie Brown states that C4 'is at heart, a factual channel' (2007: 141), adding that the broadcaster had to be, because it could never afford large quantities of domestically originated drama. This led to C4 playing a substantial role in its relationship with particular independent production companies in redesigning the terrain of factual programming and developing RTV.

Programme production on all channels in the UK has operated since the noughties in a political climate of increasing individualisation and individuation. Within this atmosphere, public discourse presents citizenship as an activity that is demonstrated through micromanaging one's happiness, health (physical, emotional and sexual) and well-being in work and relationships, through a process of introspection and self-discipline. In this way, there has been the gradual embedding and naturalisation of a 'responsibilisation culture' (see Ouellette and Hay, 2008). This rejects reliance on an interventionist and welfarist state, leading to an increasing privatisation of social problems, particularly in the area of health. Television, re-vitalised with its RTV makeover imperative, has placed itself at the centre of this shift as the cultural technology responsible for this remodelled sense of governance. Many factual programmes have moved from representing moments of change to a process of active intervention that produces these changes. As Laurie Ouellette and James Hay argue, this type of programming is,

No longer outside the logic of public service, these popular non-scripted entertainment formulas have become the domain through which television 
contributes to the re-invention of government, the re-constitution of welfare and the production of self-sufficient citizenry (2008: 480).

It is within this UK broadcast ecology and larger socio-political context that C4's turn to the telethon, raising money from television audiences and social media users for charity, as part of its medical television offering, is of interest. Jo Littler argues that whereas nineteenth century philanthropy had at its basis a 'culture of mutualism' (2015: 473), its modern late twentieth and twenty-first century incarnation is based on 'atomised individualism' (ibid). Littler draws on Michel Foucault to argue that, 'Under neo-liberalism, social policy can no longer be a counterweight to the brutality of capitalism... [T] he multiplication of the 'enterprise' form within the social body... is what is at stake in neoliberalism, and is what constitutes its "formative power" (2015: 479). What is celebrated in this regime, therefore, is individuated entertainment-celebrity action (celanthropy), corporate sponsorship and CEO philanthrocapitalism, and citizen volunteerism and donation.

The debate about healthcare in Britain continues to frame the National Health Service (NHS) as a welfarist, free-at-the point-of-use system, and to foster a consensus around protecting its sanctity and integrity. As a consequence, the massive inroads already made through processes of privatisation across almost thirty years of both Conservative and New Labour governments have been largely played down. As Youssef El-Gingihy, a general practitioner in East London, writes, 'the British public is largely unaware of this [process of privatisation] and the media, with few exceptions, have failed in their duty to inform them' (2015a: 1). He states bluntly that the NHS, in effect, merely 'lives on as a logo' (2015a: 2). This inadequacy of the mainstream broadcast and print media's response is due to the active construction of, or failure to interrogate, a persistent narrative of failing hospitals and poor care, despite spiralling costs and government claims that NHS budgets are consistently being 
increased. There is as a result very little close analysis as to where this money is effectively being spent. El-Gingihy argues, for example, that hardly anyone mentions the Private Finance Initiative schemes (PFIs) for capital expenditure, which are currently drawing money away from front line care and the financing of more expensive technology and treatments. In his 2015 book, he acknowledges the writing of Allyson Pollock (professor of public health research and policy at Queen Mary University London) and others as underpinning his arguments. It is notable that Pollock has written articles for The Guardian on the issue of PFI since at least the mid-2000s. Her visibility, and consequently the visibility of her arguments has notably lessened in this broadsheet in recent years. On the issue of PFI El-Gingihy writes that, 'the total PFI tab for the taxpayer stands at $£ 301$ billion for infrastructure projects with a capital worth of $£ 54.7$ billion' (2015a: 10). Under the circumstances of this and other forms of privatisation of health services, the charitable appeal of $S U 2 C$, as this article argues, has misplaced emphasis and is misguided in what it tries to achieve. Nor has there been sufficient media scrutiny of the extent to which internal market structures already define the system. This process goes back to the 1980s, when a purchaser-provider split (between the Primary Care Trusts and the NHS hospital trusts respectively) was implemented (El-Gingihy, 2015a: 5). The Health and Social Care Act 2012, which came into force in April 2013, sees the Primary Care Trusts and Strategic Health Authorities disbanded, replaced by Clinical Commissioning Groups which put NHS contracts out to further competitive tendering, open to the voluntary and private sectors. They are only, according to El-Gingihy, legally required to provide emergency and ambulance services (2015a: 44). All other services are provided as they are deemed appropriate, which leads, he argues to a push for rationing provision (2015a: 44). The Health Act reduces central government accountability under the guise of local empowerment. The merging of health and social care also raises the prospect, El-Gingihy (2015b) argues, that healthcare will, like social care, become means-tested, which will lead to 
top-up payments and the need for increased amounts of private insurance; the 'atomised individualism' to which Littler refers. Far from a national health system, this will make health provision more of a lottery - dependent on where one lives and the extent of one's purchasing power.

In medical research, there has long been a role for the charity sector. Cancer Research $\mathrm{UK}$, the organisation with which $\mathrm{C} 4$ is working for this telethon event, is a research and awareness charity. It comes out of the merger of two early twentieth century organisations, the Cancer Research Campaign and Imperial Cancer research fund (established 1923 and 1902 respectively). It is entirely funded by public donations, employing almost 4,000 and relying on a volunteer body of 40,000. Currently monies that the charity raises are going into the Francis-Crick Institute, a bio-medical research centre on the Euston Road in London which was planned to open at the end of 2015. The project is a partnership between Cancer Research UK, Imperial College, King's College London and University College London, the Medical Research Council and the Wellcome Trust, reflecting the huge amount of resources required for research of this kind. Whilst survival rates for certain types of cancer are rising, something that is reiterated in $S U 2 C$ as a battle being slowly won, the number of cases of cancer (because of both a longer-living and older population) and the cost of treating an individual with the disease is rising too. A BUPA 2011 report is cited as calculating that,

over the next decade the costs of cancer care in the UK are expected to rise to $£ 15.3$ billion in 2021 , which is equivalent to an average of $£ 40,000$ per person with cancer. This will mean a $62 \%$ increase in the UK's overall expenditure on cancer diagnosis and treatment, which is an increase of $£ 5.9$ billion compared with the current expenditure. (cited in NHS Choice, 2011) 
All of this leads to a climate of crisis and urgency. This sense of urgency is a key register for the telethon as live event television.

\section{The Telethon and Stand Up to Cancer (SU2C) campaign}

The $S U 2 C$ event originated as an idea in the United States of America, a country with a very strong philanthropic tradition and little public healthcare provision. It was initiated by the Entertainment Industry Foundation (EIF) on 5 September 2008 as an hour-long primetime programme televised simultaneously by the three national networks ( $\mathrm{ABC}, \mathrm{NBC}$ and $\mathrm{CBC})$ across 170 countries. Originally known as the Permanent Charities Committee, the EIF (as it became known in 1997) was established in 1942 by key members of Hollywood, notably studio bosses Samuel Goldwyn and the Warner Brothers and actors James Cagney and Humphrey Bogart. Its aim, stated on the website, is to harness 'the collective power of the entire industry to raise awareness and funds for critical health, educational and social issues in order to make a positive impact in our community and throughout the nation' (EIF Website). Across the decades it has contributed funding to the American Red Cross in WWII, to research to eradicate childhood polio and to the first screening vans for glaucoma in California. It also supports celanthropy. However, large part of its efforts has been raising money for research and treatment of a whole spectrum of cancers.

The telethon has played a key role in both BBC and ITV history. The timing of the appearance of this television 'event' maps against the start, in the UK, of the privatisation and dismantling of social welfare at a national level. The BBC, therefore, has its Children in Need (1980-present) night in November and the televising of the charity Comic Relief's Red Nose Day (1982-present) and Sport Relief (2002-present) as key points in its broadcasting calendar. As a BBC registered charity, the Children in Need webpage is part of the Corporation's archive architecture. Details of Red Nose Day and Sport Relief telethons are to be found as 
part of the Comic Relief website. Comic Relief is a separate charity running these events, the visibility of which is facilitated by being televised by the $\mathrm{BBC}$ on alternative years and populated by key talent associated with the Corporation. The ITV network ran a series of telethons in the years 1988, 1990 and 1992 that had been prompted by one of the franchises, Thames', regional telethon broadcasts in 1980 and 1985. (Details and footage from these can be found on the TV Ark Website). There was then a long period during which there was an extensive restructuring and consolidation of the ITV network, the outcome of which was the amalgamation of the two remaining franchises in England, Carlton and Granada into ITV Plc. Whilst ITV in the 2000s looked to shed its public service obligations in many areas, it brought back the telethon in the form of Text Santa (2011-present) (see the Text Santa website). This raised money for a range of UK charities to support their activities specifically over the Christmas period, as the Coalition government's austerity measures were starting to bite. In relative terms therefore, C4's broadcast of the first SU2C night in 2012 seems a late foray into this genre. However, the argument here is that it is highly strategic in its timing, in terms of a certain presentation of public service, and in its focus and mode of address, important to the channel's branding of itself as edgy and innovative.

\section{The raw and the cooked: the return of the 'live'}

As critics and industry personnel announce the death of television in the face of videogame and Internet screen cultures, there has been an increasing turn to the live event as a way of recapturing the essence and mode of address of the medium, and as a consequence enhancing its legitimacy. As Jane Feuer (1983) argues, this is how television marks its ontological and ideological history and identity. Whilst actual live broadcasts have only been a key feature of a relatively short period of television broadcasting history, as a number of academics have noted (see Bourdon, 2000; Marriott, 2007; Levine, 2008; Scannell, 2013), many programmes 
and a number of genres depend on the performance of 'liveness'. This is what Jérôme Bourdon calls the 'permanence of the rhetoric of live broadcasting' (2000: 532), eliding any sense of difference in terms of time and space between the sender and the audience. Much of the medium's claim to accountability, trustworthiness and authenticity depends on this illusion being maintained and this is done through the use of a traditional set of indices: the presenter's use of direct address to the viewing audience and their continual references to the 'now' in presenting the flow of time, the chroma-keyed word 'live' on some part of the screen. In recent times the news, the chat show, sports broadcasting and 'event' television all employ, to different degrees, elements of actual liveness (the raw) and pre-recorded footage enacted as if live, and the recorded presented as part of the past (the cooked) (Marriott, 2007: 45). Event television, from the ceremonial (royal weddings, state funerals, national observance) to the 'appointment-to-view' light entertainment shows of Strictly Come Dancing (2004-present) and The X Factor (2004-present), presupposes in its advertising, aesthetics and discourse an appeal to a national viewing audience, watching in-time onschedule. Along with these, the telethon, with its scheduling, its format, its folding-in of social media and its use of the 'television personality' (Bennett, 2010), constitutes a centripetal force of live television, intentionally drawing people back to the electronic hearth' as a national 'community' around a proclaimed 'common' purpose.

That $\mathrm{C} 4$ chose to glocalise the US SU2C format, including a number of US artists in the telethons, whilst the other broadcasters' events are more 'national' in tenor, is less surprising when one considers the broadcaster's use of American programming in its schedules and across its channel portfolio. Various academics have analysed the use of US programming at certain historical junctures in British broadcasting schedules (see Rixon, 2006; Weissmann, 2008; Woods, 2013) and a number of arguments have been made as to C4's particular use of US network brands or importing of particular programmes or genres to 
define part of its public service value (innovation) as bringing world class television to the UK (Weissmann, 2008). In this way, American presence is part of C4's national offering. The telethon offers a particular branding opportunity to a broadcaster. It emphasises the 'local' (in this case the national address as opposed to the global) through the choice of programmes utilised in the skits and more particularly through the use of particular personalities as presenters and guests during the evening. As fundraising and donations are dependent on empathy and connection to a cause, the faces used are particularly important. Attempting to draw diverse demographics together as a 'national whole' requires different modalities of address. Equally, the telethon, particularly in this medical form, runs through the spectrum of knowledge, experience and emotion, from the educational and instructive through the affective to the humorous i.e. Corner's (2002) 'discourses of sobriety' married to 'diversion'. What follows is an analysis of the use of the television personality as embodiments of these different modalities to speak about cancer.

\section{Connecting with the audience: the impact of the television personality}

Davina McCall, Alan Carr and Dr. Christian Jessen presented the SU2C telethons on C4 in 2012 and 2014. They were joined for the 2014 event (which is the focus of this article) by The Last Leg (2012-present) team, Alan Hill, Josh Widdicombe and Alex Brooker. All are arguably identified as predominantly $\mathrm{C} 4$ talent, whose television personas have been developed according to the broadcaster's remit of 'innovation' and 'distinctiveness'. Each brought elements of their persona to the presentation the event. This was highlighted by parts of the studio being divided into particular sets or spaces resonant of the genre and aesthetics of their respective shows; the chat show corner with sofa; the panel discussion layout and the clinical white laboratory space. McCall is a long-standing $\mathrm{C} 4$ presenter of factual entertainment formats. Her longest role was as the presenter of the Big Brother Eviction 
Night for the entire run of the series on the channel from 2000 to 2010 . In tune with the Zoo TV type dynamics and aesthetics that has been part of C4's move to attract the 16-34-yearold demographic, going back to its early history of 'Yoof TV' of The Word (1990-95), The Big Breakfast (1992-2002) and later Don't Forget Your Toothbrush (1994-95) (see Lury 2001 for an analysis of this programming), McCall's performance was loud, exuberant and knowing, earning her reputation as a brash, pushy 'laddette'. Her performative style involves a great deal of interplay with studio audiences as well as the home audience through direct address, breaking the televisual fourth wall. It is also both kinetic and physical. She is often on shows that require her to move quickly between a studio and outside space which emphasises her energy and vitality. This is something that is key to the sense of urgency in $S U 2 C$ as to the 'medical emergency', but also to the excitement required to keep pushing up the fundraising total. This brashness has been, however, over the years, tempered by a public biography figuring vulnerability. The repeat elements of press stories of her life are a childhood spent with grandparents because of divorced parents and an absent but later returned father, but an estranged French mother, never reconciled. Cancer also figures in this biography, as she lost her half sister to the disease in 2012 (Betiku, 2012). Some of the strongest elements of her persona that have been developed in more recent years are, therefore, those of empathy, sympathy and affinity. These have been particularly shored up by her role, not in a C4 but an ITV series Long Lost Family (2011-present); a programme about long-term family separation, with the goal of an on-screen reunion. Much of the publicity around this series emphasises McCall's genuineness, openness and sense of connection with the people in the show. This had, arguably, been prefigured by her appearance in the family genealogy series Who Do You Think You Are? (Series 6, 2009) (2004-present), the structure and aesthetics of which presents the celebrity/personality as familiar, familial, accessible, affective and affected. As Amy Holdsworth argues, 'the stress 
is on emotion and experience as modes of knowledge' (2010: 235); a stress that is also evident in $S U 2 C$. McCall responds to people by hugging them, holding them, and embracing them. On many occasions, she is depicted close to tears or unable to speak lines because she is so emotionally affected. The highs and lows of this 'spectacularisation of celebrity suffering' (see Lim and Moufahim, 2015) were encapsulated in the BBC behind-the-scenes documentary Davina - Beyond Breaking Point for Sport Relief (2014), documenting her 2014 triathlon for the charity. (For some commentators, this celebrity mediation of suffering can hit the wrong register. Martin Scott (2014) cites the example of a viewer interviewee discussing McCall's response where she is out in Africa for charity, to both a mother and child dying in childbirth. The viewer's memory of this scene is more focused around McCall's sorrow and her presence somewhere so 'frigging dire' as demonstrating that 'she is not living a charmed life and [that] she is mucking in...' (cited in Scott, 2014: 458) than it is for the loss of two lives. This, Scott argues, is misplaced connectivity). SU2C requires an anchoring voice and presence which can, as argued above, move between the registers of boisterous and subdued; between 'diversion' and 'sobriety'. The evening is interspersed with filmed personal stories of ordinary people living with, or dying from, cancer. They are clearly chosen to demonstrate how the disease hits all ages and the impact not only on the person with the disease, but also on family and friends. There is a narrative about the concern of leaving a long-term partner behind; of not growing old together (Pauline's Story). Both Shannon's and Lloyd's stories are about young people, 19 and ten respectively, and are about missed opportunities and unfulfilled potential. Lloyd's story is about having a future as a potential professional footballer cut short (he was diagnosed with cancer just after having been chosen for one of the junior premier League teams). Shannon's tale, which is one of terminal cancer, is about missing out on her and others' life stages - falling in love, having children, seeing her brother and her friends' lives develop. All three films celebrate the 
bravery and other-centeredness of these voices, whilst providing space to also depict the deep sense of sadness and bewilderment through the voices of parents and siblings. It is Shannon's story that brings McCall close to tears and she only just able to introduce the section. It is these associations of personal engagement, commitment, emotionality, and in the expression of these, an ordinariness, that make her the perfect foil to the voice of the television expert and medical authority for $S U 2 C$, Dr. Christian Jessen.

Jessen became a television face as one of the medical experts on C4's long running reality TV show Embarrassing Bodies. Whilst daytime television had introduced the medical voice (for example, Dr Chris Steele on the ITV lifestyle programme This Morning (1988present)), discussing giving up smoking, through the symptoms of menopause to conducting breast examinations and cervical smear tests live on air, Embarrassing Bodies took the notion of health taboos and facing up to one's fears and concerns as the sole subject of the series. Jessen's upper-middle class demeanour, medical training credentials (studying at University College London and the London School of Hygiene and Tropical Medicine, now involved in international and Harley Street consultancy) provide both the discourse of sobriety and authority as well as a level of 'the non-mainstream' that is the balance that SU2C2014 attempts to find in establishing its particular brand of public service. It was, as the 2014 Annual Report stated, 'crucial that it felt very Channel 4: that the tone captured the audience's imagination and that we were able to deliver a serious and important message in a programme that was also entertaining and fun' (2014: 54). This balance is demonstrated by a key sequence in the 2014 event, as McCall joins Jessen in his 'science lab' quarter of the studio where she and the audience are tested by the doctor in relation to dispelling myths about what will cause cancer and what will help avoid cancer. At this point, McCall stands in, importantly alongside the studio audience, for the non-specialist/enthusiastic amateur with a whole-hearted belief in certain claims and health assertions. One of the questions is 'do 
superfoods prevent you from getting cancer,' to which McCall responds with a resounding and enthusiastic 'yes', only to be informed by Jessen that 'there is no such thing as a superfood'. He ribs her: 'it is a marketing trick to make people like you buy blueberries...ouch!', before turning straight to camera to deliver the authoritative message and 'correct advice' of 'keeping a healthy body weight, being sensible in the sun, not smoking, not drinking excessively and living as active a lifestyle as you can'. The formal educating voice, however, is only one register in the public service repertoire of this programme. The next section analyses a very different register used to address the issue of cancer.

\section{Cancer and taboo: comedy and gendered discourse}

In $S U 2 C$ 2014, the audience, both at home and in the studio, is urged to think differently about cancer; not to be fearful and to ignore warning signs, but rather to learn to think about and read the body with a (new) perspective. Part of this is about learning to talk about bodily functions and dysfunction without embarrassment. The programme uses comedy to puncture the notion of cancer as taboo and as bodily abjection. This is, in one sense, a register easier for $\mathrm{C} 4$ as a broadcaster to achieve, given its approach to taboo and humour across its history. The carnivalesque and camp are two strategies for this and they are embodied in $S U 2 C$ by the television presenter and chat show host Alan Carr. Carr has had a longstanding relationship with the channel in the chat show genre (The Friday/Sunday Night Project (2005-9) and Alan Carr: Chatty Man (2009-present)). The style and presentation of Carr's performance fits into a restyling and revamping of the talk show interview to meet stand-up comedy, foregrounding different performances of 'boys-behaving-boisterously-and badly'; the mainstreaming of a form of New Laddism (see Benyon, 2001). 
Carr's performance in SU2C 2014 of high camp masculinity, however, was overshadowed by the performance of The Last Leg team of Alan Hill, Josh Widdicombe and Alex Brooker. The Last Leg was a niche magazine programme also contesting perceptions of the body, being part of C4's 'coverage' of the Paralympic Games of 2012. There was a concern to move the Paralympics beyond the 'worthy' and the 'educational', getting away from viewing disability as 'otherness' observed from a distance. This was emphasised by the broadcaster deciding to reconsider its original strategy and dedicate its main channel to the Games rather than hiving off parts of the coverage to other channels in its portfolio. This was one part of making the viewing, debates and discussion of the Paralympics 'mainstream'. 'Taking a different view' $(\mathrm{C} 4,2012)$ was a key aspect of the broadcaster's marketing of the Games. As the 2012 Annual Report states, 'Meet the Superhumans' (as the C4 marketing campaign for the Paralympics was entitled, emphasising prowess and intense effort) set the tone for the approach to the events, mixing 'arresting imagery of disabled bodies in training, competition and at rest with scenes that conjured up the back-stories of the athletes ... with swagger and scale' (2012: 24). The Last Leg used comedy as a form of 'swagger'; as a structure to carve out a space for open discussion, addressing head-on the awkwardness of able-bodied people in talking about and asking questions about disabilities. It relied on three aspects to succeed. Firstly, it made the able-bodied voice the minority in its presenting team. The tag-line for the show was 'Four Men, Three Legs,' as both the Australian stand-up comedian Hill and at that time new-to-TV-talent Brooker have each a prosthetic leg and Brooker has a hand and arm deformity. Following stand-up conventions, which Gerald Matte and Ian McFadyen argue have a particular ability to 'reframe social permissions' (2011: 161), the presenting team not only responded to some of what could have been considered the more outrageous studio and home audience questions and comments by 'pushing the envelope' further still, but in 'owning the identity', Hill and Brooker also initiated some of the edgier 
humour. In this way, the programme located itself in the recent history of 'boys-behaving badly' television mentioned above. Finally, the programme arguably relied on the history of $\mathrm{C} 4$ as the channel that pushes against taboos and that has relied on its remit to present alternative views' and 'to stimulate debate' to challenge the boundaries of what more conservative critics would consider taste and decency.

This strategy of getting people to speak about subjects from which society usually shies away and using comedy to breach those boundaries, is used in SU2C 2014 to discuss prostate cancer and the male body as a site of medical intervention and investigation. The audience and studio guests are enjoined by The Last Leg team to come up with slogans for 'Talking about Cancer'; a permission to mix ribaldry with raising awareness (one of the tamer ones being: 'don't take a chance, put a hand down your pants'). This laddishness is further 'sanctioned' by the guest appearance of another C4 'face' of RTV, Kirsty Allsopp. Her personal story of losing her mother to breast cancer and of how she and her sister are possibly genetically predisposed to the disease is used to voice and validate the position of being aware and prepared, although potentially frightened. Her sister, the audience is told, has taken the precautionary step of a preventative mastectomy. Allsopp herself has taken the decision not go down that route, stating that she is not that brave. In line with the presentation of masculinity in the discussion as uncomfortable with examination and potential vulnerability, she turns at one point away from the internal conversation of The Last Leg studio space and calls across to Dr. Jessen in his clinical/advisory space as to how often prostate examinations should be undertaken, in comparison to the once-every-three years cervical smear examination advised to women. When told that there is no particular need for a regular examination, only when certain symptoms show themselves, her response is 'Manup, you guys'. She provides a female tempering of the otherwise all-male set up of this section, at one and the same time with this phrase both chastising, but also underpinning, the 
masculinity being performed. In this way, she brings to the tenor of the segment the straighttalking, honest and self-appraising femininity and a discourse of comedic gendered competition and competitiveness associated with her television persona (for a more detailed analysis of this persona see Charlesworth, forthcoming).

\section{Conclusion}

If one sees the state of the UK health service and the circumstances of cancer research financing and treatment provision as a consequence of a neo-liberal project in the making for over thirty years, $\mathrm{C} 4$ as a product of this history is caught between offering a critique of these and other socio-economic/structural crises, and offering solutions based largely on a model of a more pro-active citizenry; the central dynamic of factual entertainment formats today. Proactiveness is defined in its privatised form as taking care of oneself and responding in a more individuated and individual ways, such as donating to charity. The connectivity of the 'public good' is lost to a collective self-help. In this way in the UK, just as in the USA, we '... substitute general tax collections with voluntary revenue enhancers' (King, 2006: xxvii). It is unsurprising, therefore, that the telethon has emerged as a format in this era and that the overtly medical version is its latest iteration. Making up the gaps in state funding of sustained medical research through the championing of philanthropy, becomes the public service voice in this political climate. Whilst there has been much to celebrate, as Paul Rixon (2006) and others have argued in their work, this type of incorporation of American presence in the UK broadcasting schedule, should perhaps, however, not be looked upon with equanimity.

\section{References}


Abraham D (2011) What We're 4, a speech given to the Royal Television Society. 23 May. Available at: https://rts.org.uk/sites/default/files/David-Abraham-2011.pdf. (accessed 17 August 2015)

Alan Carr: Chatty Man (2009-present). Channel 4. Open Mike Productions.

Bennett J (2010) Television personalities: stardom and the small screen. London: Routledge. Benyon J (2001) Masculinities and culture, Maidenhead, Open University Press. Betiku F (2012) Davina McCall opens up about the loss of her half-sister to cancer. Daily Mail Online, 14 October. Available at: http://www.dailymail.co.uk/tvshowbiz/article2217586/Davina-McCall-opens-death-half-sister-Caroline.html (accessed 5 January 2016).

Big Breakfast, The (1992-2002). Channel 4. Planet 24 Productions.

Big Brother Eviction Night (2000-10). Channel 4. Endemol.

Bourdon J (2000) Live television is still alive: on television as an unfulfilled promise. Media, Culture \& Society 22(5): 531-556.

Brown M (2007) A licence to be different: the story of Channel 4. London: BFI.

Channel Four (2014) Britain's Creative Greenhouse: Channel 4 Annual Report 2014. Available at: http://annualreport.channel4.com/ (accessed 30 August 2015). Channel Four (2012) Channel Four Television Corporation Report and Financial Statement 2012. Available at: http://annualreport.channel4.com/ (accessed 31 August 2015).

Charlesworth D (forthcoming) From homebuyer to angel of the hearth: the development of Kirstie Allsopp as the female face of Channel 4 'Squeezed Middle' Austerity Programming. In: O'Callaghan C and Davies H (eds) Gender and economics in popular culture: femininity, masculinity and austerity in film and TV. London: I.B. Tauris.

Children in Need (1980-present). BBC 1. BBC.

Comic Relief: Red Nose Day (1988-present). BBC1. BBC. 
Comic Relief: Sport Relief (2002-present). BBC1. BBC.

Corner J (2002) Performing the real: documentary diversions. Television and New Media 3(3): 255-269.

Davina - Beyond Breaking Point for Sport Relief (2014). BBC2. BBC.

Don't Forget Your Toothbrush (1994-1995). Channel 4. Ginger Productions, Buena Vista Television.

Dovey J (2000) Freakshow: first person media and factual television. London: Pluto Press. El-Gingihy Y (2015a) How to Dismantle the NHS in 10 Easy Steps. Winchester: Zero Books. El-Gingihy Y (2015b) The NHS is on a one-way road to privatisation. Guardian, 2 October. Available at: http://www.theguardian.com/healthcare-network/2015/oct/02/nhs-oneway-road-privatisation (accessed 3 October 2015).

Embarrassing Bodies (2007-15). Channel 4. Maverick Television.

Feuer J (1983) The concept of live television: ontology as ideology. In: Kaplan EA (ed) Regarding Television. American Film Institute, pp. 12-21.

Friday/Sunday Night Project, The (2005-09). Channel 4. Princess Productions.

Holdsworth A (2010) Who do you think you are?: family history and memory on British television. In: Gray A and Bell E (eds) Televising History: Mediating the Past in PostWar Europe. Houndsmill: Palgrave MacMillan, pp. 234-247.

Jamie's Ministry of Food (2008). Channel 4. Fresh One Productions. Jamie's School Dinners (2005). Channel 4. Fresh One Productions. Jamie's Sugar Rush (2015). Channel 4. Fresh One Productions. King S (2006) Pink Ribbons, Inc. breast cancer and the politics of philanthropy. Minneapolis, University of Minnesota.

Last Leg, The (2012-present). Channel 4. Open Mike Productions. 
Leadley A (2015) Supersize vs. Superskinny: re-framing the freakshow in contemporary popular culture. Journal of Popular Television 3(2): 213-228.

Levine E (2008) Distinguishing television: the changing meanings of television liveness. Media, Culture \& Society 30(3): 393-409.

Lim M and Moufahim M (2015) The spectacularization of suffering: an analysis of the use of celebrities in Comic Relief UK's Charity Fundraising Campaigns. Journal of Marketing Management 31(5-6): 525-545.

Littler J (2015) The New Victorians? Celebrity Charity and the Demise of the Welfare State. Celebrity Studies 6(4): 471-485.

Long Lost Family (2011-present). ITV. Wall to Wall Media, Shed Media et. al.

Lury (2001) British youth television: cynicism and enchantment. Oxford: Oxford University Press.

Marriott S (2007) Live television: time and space and the broadcast event. London: Sage Publications.

Matte G and McFadyen I (2011) Can We Talk? The Reframing of Social Permissions in the Comedy of Joan Rivers. Comedy Studies 2(2): 161-171.

NHS Choices (2011) Cancer survival rates threatened by rising costs. 12 December. Available at: http://www.nhs.uk/news/2011/12December/Pages/cancer-treatment-cost$\underline{\text { may-increase.aspx }}$ (accessed 31 August 2015)

O’Brien Hill GE (2014) The Older Mother in One Born Every Minute. In: Whelehan I and Gwynne J (eds) Ageing, Popular Culture and Contemporary Feminism: Harleys and Hormones. Houndsmill: Palgrave MacMillan, pp. 187-203.

One Born Every Minute (2010-present). Channel 4. DragonFly Film and Television Productions, Shine Group. 
Ouellette L and Hay J (2008) Better living through reality TV: television and post-welfare citizenship. Oxford: Blackwell Publishing.

Rixon P (2006) American television on British screens: a story of cultural interaction. Houndsmill: Palgrave MacMillan.

Scannell P (2013) Television and the meaning of live. London: Polity Press.

Scott M (2015) The role of celebrities in mediating distant suffering. International Journal of Cultural Studies 18(4): 449-466.

Stand Up to Cancer (2012 \& 2014). Channel 4. Channel 4, Cancer Research UK.

Strictly Come Dancing (2004-present). BBC 1. BBC.

Supersize vs. Superskinny (2008-present). Channel 4. Remarkable Television.

Text Santa (2011-present) ITV. ITV Studios.

This Morning (1988-present). ITV. Granada Television.

Weissmann E (2008) Negotiating American quality: the NBC brand in Britain. Critical Studies in Television 3(2): 40-58.

Who Do You Think You Are? (2004-present). BBC2 (2004-2006), BBC1 (2006-present).Wall to Wall.

Woods F (2013) Teen TV meets T4: assimilating The OC into British youth television. Critical Studies in Television 8(1): 14-35.

Word, The (1990-95). Channel 4. Planet 24 Productions.

X Factor, The (2004- present). ITV. Syco Entertainment, Thames, Fremantle Media.

\section{Author Biography}

Diane Charlesworth is Senior Lecturer in Film, Television and Cultural Studies at the University of Lincoln. Her research areas are star and celebrity studies, gender representation and discourse analysis and British broadcasting history. She has published in Celebrity 
Studies and has a book chapter forthcoming, and is currently researching the development of female talent in early British television. 